\title{
Características dos componentes não integrantes da carcaça de novilhos superjovens da raça Devon, terminados em diferentes sistemas de alimentação
}

\author{
[Characteristics of non-integrant components of carcass of Devon young steers, \\ finished in different feeding systems]
}

\author{
L.F.G. Menezes ${ }^{1}$, I.L. Brondani ${ }^{2}$, J. Restle ${ }^{2}$, D.C. Alves Filho ${ }^{3}$, A.M. Callegaro ${ }^{4}$, M. Weise ${ }^{5}$ \\ ${ }^{1}$ Universidade Tecnológica Federal do Paraná \\ Estrada para Boa Esperança, Km 04 \\ 85660-000 - Dois Vizinhos, PR \\ ${ }^{2}$ Aluno de pós-graduação - UFSM. Bolsista CNPq \\ ${ }^{3}$ Departamento de Zootecnia - UFSM - Santa Maria, RS \\ ${ }^{4}$ Aluno de graduação - UFSM. Bolsista FAPERGS \\ ${ }^{5}$ Aluno de graduação - UFSM. Bolsista PRAE \\ RESUMO
}

\begin{abstract}
O objetivo do estudo foi avaliar as características dos componentes não integrantes da carcaça de novilhos Devon terminados em confinamento (CONF), em pastagem de clima temperado (pastagem de azevém Lolium multiflorum Lam - PTEM) ou em pastagem de clima tropical (associação de pastagem de milheto - Pennisetum americanum (L.) Leeke - e capim-papuã - Bracharia plantaginea - PTRO). Os novilhos, ao início da terminação, estavam com $320 \mathrm{~kg}$ e 15 meses de idade. Os animais confinados foram alimentados com relação volumoso:concentrado de 60:40; o volumoso era constituído de silagem de milho, e o concentrado de farelo de trigo, milho e minerais. Os animais foram abatidos com pesos semelhantes de 388,3; 386,7 e 375,8kg no CONF, na PTEM e na PTRO, respectivamente. Os animais da PTRO apresentaram maior $(\mathrm{P}<0,10)$ rendimento de carcaça quente $(\mathrm{RCQ})$ relativo a $100 \mathrm{~kg}$ de peso corporal vazio (RCQPCV) do que os da PTEM, 64,6 versus 62,6\%, e os do CONF apresentaram RCQPCV intermediário, 63,7\%. Os pesos absolutos do fígado, 5,22; 4,43 e 3,87kg, do conjunto dos órgãos internos, 12,81; 11,37 e 10,83kg, do rúmen-retículo, 7,62; 6,54 e 6,06kg, da gordura do coração, 1,26; 0,65 e 0,30kg, e dos intestinos, 9,97; 7,13 e 7,49kg, foram mais altos $(\mathrm{P}<0,05)$ nos animais da PTEM, em relação aos do CONF e da PTRO, respectivamente. A mesma ordem de grandeza ocorreu com os pesos relativos desses órgãos. A PTRO e o CONF originaram animais com maior $(\mathrm{P}<0,05)$ peso de conteúdo gastrintestinal em relação à PTEM, respectivamente, 60,27; 55,32 e 41,21kg. O CONF proporcionou animais com pesos absolutos mais elevados $(\mathrm{P}<0,05)$ do omaso, $5,17 \mathrm{~kg}$, em relação aos da PTEM, 3,70kg, e este peso foi intermediário nos animais da PTRO, 4,77kg. A mesma ordem de grandeza ocorreu com os pesos relativos do omaso, 1,61; 1,12 e 1,54\%.
\end{abstract}

Palavras-chave: azevém, confinamento, milheto, peso de corpo vazio, rendimento de carcaça

\begin{abstract}
The non-integrant components of carcass of Devon steers were evaluated. Animals were finished in feedlot (CONF), winter pasture (pasture of ryegrass - Lolium multiflorum Lam -PTEM), or tropical pasture (association of millet pasture - Pennisetum americanum (L.) Leeke - and Alexander Grass Brachiaria plantaginea - PTRO). At the beginning of finishing, the average weight of steers was $320 \mathrm{~kg}$ and age was 15 months. The roughage:concentrate ratio of CONF was 60:40. The animals were slaughtered at similar weights of 388.3, 386,7, and 375.8 for CONF, PTEM, and PTRO, respectively. The PTRO animals showed higher hot carcass dressing (HCD) percentage relative to $100 \mathrm{~kg}$ of empty body weight (HCDEBW) in comparison to PTEM (64.6 versus 62.6\%), and CONF animals showed
\end{abstract}

Recebido em 17 de março de 2009

Aceito em 3 de março de 2011

E-mail: luismenezes@utfpr.edu.br

Projeto financiado pelo CNPq. 
intermediary value for HCDEBW (63.7\%). The absolute weights of liver, 5.22, 4.43, and 3.87kg; total weights of all internal organs, 12.81, 11.37, and 10.83kg; rumen-reticulum, 7.62, 6.54, and 6.06kg; heart fat, $1.26,0.65$, and $0.30 \mathrm{~kg}$; and intestines, 9.97, 7.13, and $7.49 \mathrm{~kg}$, were higher $(P<0.05)$ in PTEM animals than in CONF and PTRO animals, respectively. The same differences were observed concerning relative weights of the same organs. PTRO and CONF animals showed higher $(P<0.05)$ gastrointestinal content than PTEM animals, 60.27, 55.32, and $41.21 \mathrm{~kg}$, respectively. Feedlot finished animals exhibited higher absolute weight of omasum, $5.17 \mathrm{~kg}$, than PTEM animals, $3.70 \mathrm{~kg}$, and PTRO animals presented intermediary value, $4,77 \mathrm{~kg}$. The same order was observed concerning relative weigh of the omasum, 1.61, 1.12 , and $1.54 \%$.

Keywords: ryegrass, feedlot, millet, empty body weight, carcass dressing percentage

\section{INTRODUÇÃO}

O Brasil é um país continental, com grande potencial pecuário em todo território nacional. No entanto, pela grande extensão, existem vários sistemas de criação empregados na pecuária bovina. Nas regiões Centro-Oeste, Sudeste e Norte, a terminação de bovinos predominante é em pastagens tropicais, com grande presença do confinamento, principalmente no Sudeste brasileiro. Já na região Sul, a pastagem temperada é o principal meio de terminação dos animais, com pequena parcela dos animais sendo terminada em confinamento (Anuário..., 2006).

Com essa heterogeneidade nos sistemas de alimentação, podem existir variações nas exigências nutricionais dos animais devido, principalmente, a diferenças no desenvolvimento de órgãos com grande exigência nutricional, como o fígado e o trato gastrintestinal (Nutrient..., 1996). Pacheco et al. (2005) observaram correlação entre peso de fígado (em valores absolutos) e a exigência de energia líquida de mantença (Mcal) de 0,57. Lunt et al. (1986) verificaram que a raça, o ganho de peso diário e a dieta influenciaram na massa de órgãos internos, pois novilhos alimentados com dietas à base de volumosos apresentaram maiores pesos de coração e fígado que os alimentados à base de grãos.

Além de diferenças nas exigências nutricionais, os diferentes pesos dos constituintes não integrantes da carcaça são importantes sob o ponto de vista dos frigoríficos, uma vez que a venda dos subprodutos é significativa fonte de renda para esse segmento. Entre os subprodutos, o couro é, sem dúvida, o componente de maior importância, se considerado o valor agregado que recebe do abate até a transformação em produtos comerciais (Restle et al., 2005).
Além disso, do ponto de vista do produtor, as partes não integrantes da carcaça - órgãos internos, cabeça, couro, sangue, patas e gordura visceral - são importantes, pois tendem a variar de acordo com a raça e a dieta, influenciando diretamente o rendimento de carcaça (Macitteli et al., 2005). Diferente de animais criados nos Estados Unidos, que recebem dietas com altos teores de concentrado, na Austrália e Nova Zelândia, que apresentam grande participação de pastagens temperadas na dieta, o peso do conteúdo do trato gastrintestinal, em relação ao peso corporal vazio, é alto em bovinos criados no Brasil. Os principais fatores que levam a isso são a baixa digestibilidade das forragens utilizadas em sistema de pastejo e/ou a alta relação volumoso:concentrado das dietas utilizadas em sistemas de confinamento (Gesualdi Jr. et al., 2001). A digestibilidade, associada às características estruturais das gramíneas tropicais, determina a taxa de passagem da dieta e, consequentemente, o maior enchimento do trato gastrintestinal (Wilson, 1997), o que não acontece em sistemas de pastejo no Sul do Brasil, que utilizam pastagens temperadas, de maior digestibilidade e, consequentemente, maior taxa de passagem.

O objetivo do presente estudo foi avaliar o efeito da terminação de novilhos da raça Devon em confinamento, em pastagem temperada ou em pastagem tropical sobre os componentes não integrantes da carcaça.

\section{MATERIAL E MÉTODOS}

O experimento foi realizado no Departamento de Zootecnia da Universidade Federal de Santa Maria (UFSM), situada na Depressão Central do Rio Grande do Sul, numa altitude de $95 \mathrm{~m}$, latitude de $29^{\circ} 43^{\prime}$ sul e longitude $53^{\circ} 42^{\prime}$ oeste. O 
clima da região é classificado como Cfa, subtropical úmido.

$\mathrm{O}$ experimento foi dividido em duas fases. $\mathrm{Na}$ primeira fase, foram utilizados nove animais da raça Devon, oriundos de monta tradicional (novembro a fevereiro), que, ao início do experimento, apresentavam 320kg e 15 meses de idade. Quatro destes animais foram terminados em confinamento (CONF) e cinco em pastagem tropical (associação de milheto - Pennisetum americanum (L.) - com capim-papuã Brachiaria plantaginea) - PTRO). Na segunda fase, foram utilizados oito animais de mesma procedência, raça, peso e idade dos animais da primeira fase, porém oriundos de monta de outono (abril e maio). Essa diferenciação ocorreu para que os animais terminados no inverno apresentassem a mesma idade inicial dos terminados no período de verão. Do grupo de monta de outono, quatro animais foram terminados em confinamento e quatro animais em pastagem temperada (azevém - Lolium multiflorum Lam - PTEM). Foi realizada análise de variância entre as duas fases de confinamento (verão e inverno), e, como não foram observadas diferenças, os dados foram agrupados em apenas um tratamento.

Os animais terminados exclusivamente em pastagem receberam como suplemento mineral cloreto de sódio à vontade. Os terminados em confinamento, tanto no verão como no inverno, receberam dieta com relação volumoso:concentrado de 60:40 (base na matéria seca). O volumoso era constituído de silagem de milho, e o concentrado continha farelo de trigo, grão de milho, calcário calcítico, cloreto de sódio e ionóforo (monensina sódica). A dieta foi calculada segundo o NRC (Nutrient..., 1996), para que os animais atingissem ganho de peso médio diário (GMD) de 1,200kg.

Os teores de proteína bruta e fibra em detergente neutro da dieta foram obtidos por meio da metodologia descrita pelo AOAC (Official..., 1984). O NDT foi calculado segundo metodologia descrita por Weiss et al. (1992), sendo o NDT multiplicado por 4,4 para a obtenção da energia digetível (Nutrient..., 1996) - Tab. 1.

Tabela 1. Composição bromatológica das dietas experimentais

\begin{tabular}{|c|c|c|c|c|}
\hline \multirow[t]{2}{*}{ Componente } & \multirow[t]{2}{*}{ Matéria seca, \% } & $\begin{array}{c}\text { Proteína bruta, } \\
\%\end{array}$ & $\begin{array}{c}\text { Energia } \\
\text { digestível } \\
\text { Mcal/kg MS }\end{array}$ & $\begin{array}{c}\text { Fibra em } \\
\text { detergente } \\
\text { neutro, \% }\end{array}$ \\
\hline & & \multicolumn{3}{|c|}{-- na matéria seca - } \\
\hline Silagem de milho & 26,33 & 9,18 & 2,80 & 47,53 \\
\hline Concentrado & 88,39 & 11,33 & 3,53 & 15,31 \\
\hline Pastagem temperada $^{1}$ & 17,37 & 22,70 & 3,00 & 32,95 \\
\hline Pastagem tropical $^{2}$ & 29,90 & 9,63 & 2,87 & 52,83 \\
\hline
\end{tabular}

${ }^{1}$ Simulação de pastejo de pastagem de azevém.

${ }^{2}$ Simulação de pastejo de pastagem com associação de milheto e capim-papuã.

A cada 21 dias, os animais foram pesados após jejum de líquidos e sólidos de 14 horas. O período de terminação foi variável conforme o sistema de alimentação. Os animais terminados em confinamento levaram 47 dias, os da pastagem temperada 75 dias e os da pastagem tropical 100 dias para atingirem o peso préestipulado. Essa variação ocorreu devido aos diferentes GMD - 1,410; 1,200 e 0,666kg -, respectivamente.

Quando a média do tratamento se aproximava de $380 \mathrm{~kg}$ de peso vivo, os animais, submetidos a jejum de sólidos e líquidos de 12 horas, foram pesados para se obter o peso de abate. No momento do abate, foram coletados os pesos dos seguintes componentes: sangue; cabeça (incluindo orelhas e chifres), vassoura da cauda, patas e couro - denominados componentes externos -; coração, rins, fígado, baço e pulmões - denominados órgãos internos -; rúmenretículo, omaso, abomaso e intestinos delgado e grosso - denominados trato gastrintestinal vazio -; e gorduras inguinal, renal, ruminal, do coração e de toalete - denominadas gorduras internas.

As meias-carcaças (direita e esquerda) foram identificadas, sendo o peso da carcaça quente 
obtido anteriormente à sua entrada na câmara de resfriamento. O peso de corpo vazio foi obtido pelo somatório dos pesos da carcaça quente, sangue, componentes externos, órgãos vitais, trato gastrintestinal vazio e gorduras internas. Após 24 horas de resfriamento em câmara fria a $2^{\circ} \mathrm{C}$, as carcaças foram novamente pesadas, obtendo-se o peso de carcaça fria. A partir dos pesos de abate, do corpo vazio, da carcaça quente e da carcaça fria, calcularam-se os rendimentos de carcaça quente e fria em relação ao peso de abate e do corpo vazio.

O delineamento experimental utilizado foi o inteiramente ao acaso, com três tratamentos e número variável de repetições - oito para o confinamento, cinco para a pastagem tropical e quatro para a pastagem temperada -, considerando-se cada animal uma unidade experimental. Os dados foram submetidos à análise de variância, e as médias comparadas pelo teste $t$, por meio do pacote estatístico SAS/2000. Também foi realizado o estudo de correlação entre as variáveis dependentes por meio do cálculo do coeficiente de correlação de Pearson.

\section{RESULTADOS E DISCUSSÃO}

$\mathrm{O}$ peso do corpo vazio (PCV) não foi influenciado pelo sistema de alimentação (Tab. 2), o que está ligado à estipulação do mesmo peso de abate (PAB) para todos os tratamentos. Menezes et al. (2007) observaram correlação de 0,93 entre o PCV e o PAB, em novilhos oriundos do cruzamento rotativo Charolês-Nelore terminados em confinamento. No presente estudo, as correlações entre essas variáveis foi de $0,97 \quad(\mathrm{P}<0,0001) ; \quad 0,99 \quad(\mathrm{P}=0,0574)$ e 0,93 $(\mathrm{P}=0,0230)$ para os animais do confinamento, da pastagem temperada e da pastagem tropical, respectivamente.

Tabela 2. Médias e erros-padrão das médias dos pesos de abate (PAB) e do corpo vazio (PCV), relação entre PCV e PAB, rendimentos de carcaça quente e fria em relação ao PCV (RCQPCV e RCFPCV), pesos absolutos e relativos de sangue e dos órgãos vitais de novilhos da raça Devon, de acordo com o sistema de alimentação

\begin{tabular}{lccc} 
& Confinamento & Pastagem temperada & $\begin{array}{c}\text { Pastagem }^{1} \\
\text { tropical }^{2}\end{array}$ \\
\hline Peso de abate, kg & $388,3 \pm 9,2$ & $386,7 \pm 15,1$ & $375,8 \pm 11,7$ \\
Peso de corpo vazio, kg & $322,4 \pm 7,1$ & $330,4 \pm 11,1$ & $309,9 \pm 8,9$ \\
PCV/PAB & $0,83 \pm 0,006 \mathrm{AB}$ & $0,85 \pm 0,011 \mathrm{~A}$ & $0,82 \pm 0,007 \mathrm{~B}$ \\
RCQPCV, \% & $63,67 \pm 0,4 \mathrm{AB}$ & $62,57 \pm 0,9 \mathrm{~B}$ & $64,59 \pm 0,5 \mathrm{~A}$ \\
RCFPCV, \% & $62,03 \pm 0,4$ & $61,41 \pm 0,8$ & $62,78 \pm 0,6$ \\
Sangue, kg & $9,56 \pm 0,6 \mathrm{a}$ & $8,87 \pm 0,9 \mathrm{ab}$ & $6,84 \pm 0,7 \mathrm{~b}$ \\
Sangue, \% do PCV & $2,97 \pm 0,2 \mathrm{a}$ & $2,70 \pm 0,3 \mathrm{ab}$ & $2,21 \pm 0,2 \mathrm{~b}$ \\
Coração, kg & $1,31 \pm 0,05$ & $1,37 \pm 0,09$ & $1,37 \pm 0,07$ \\
Coração, \% PCV & $0,41 \pm 0,02$ & $0,42 \pm 0,03$ & $0,44 \pm 0,02$ \\
Pulmão, kg & $3,80 \pm 0,2$ & $4,12 \pm 0,3$ & $3,69 \pm 0,2$ \\
Pulmão, \% PCV & $1,19 \pm 0,06$ & $1,25 \pm 0,10$ & $1,19 \pm 0,08$ \\
Rins, kg & $0,73 \pm 0,04$ & $0,85 \pm 0,07$ & $0,70 \pm 0,05$ \\
Rins, \% PCV & $0,23 \pm 0,01$ & $0,26 \pm 0,02$ & $0,23 \pm 0,02$ \\
Fígado, kg & $4,43 \pm 0,20 \mathrm{~b}$ & $5,22 \pm 0,30 \mathrm{a}$ & $3,87 \pm 0,30 \mathrm{~b}$ \\
Fígado, \% PCV & $1,37 \pm 0,05 \mathrm{~b}$ & $1,58 \pm 0,08 \mathrm{a}$ & $1,25 \pm 0,06 \mathrm{~b}$ \\
Baço, kg & $1,10 \pm 0,10$ & $1,25 \pm 0,16$ & $1,20 \pm 0,12$ \\
Baço, \% PCV & $0,34 \pm 0,03$ & $0,38 \pm 0,06$ & $0,39 \pm 0,04$ \\
COI, kg & $11,37 \pm 0,3 \mathrm{~b}$ & $12,81 \pm 0,4 \mathrm{a}$ & $10,83 \pm 0,3 \mathrm{~b}$ \\
COI, \% PCV & $3,54 \pm 0,09 \mathrm{~b}$ & $3,88 \pm 0,13 \mathrm{a}$ & $3,49 \pm 0,11 \mathrm{~b}$ \\
\hline
\end{tabular}

Valores seguidos por letras minúsculas e maiúsculas diferentes, na linha, diferem entre si pelo teste $\mathrm{t}(\mathrm{P}<0,05)$ e $(\mathrm{P}<0,10)$, respectivamente.

${ }^{1}$ Pastagem de azevém.

${ }^{2}$ Pastagem com consorciação de milheto e capim-papuã.

COI: conjunto dos órgãos internos. 
Segundo Owens et al. (1995), várias equações de regressão foram criadas para estimar o peso corporal vazio por meio do peso vivo, sendo que o PCV correspondeu de 85 a 95\% do peso corporal. O resultado da relação PCV/PAB do presente estudo ficou bem próximo do preconizado pelo NRC (Nutrient..., 1996), de 0,89 .

Os animais da pastagem temperada apresentaram maior $(\mathrm{P}<0,10)$ relação $\mathrm{PCV} / \mathrm{PAB}$ do que aqueles da pastagem tropical. A digestibilidade das forrageiras influenciou nesse resultado, uma vez que a pastagem temperada apresentou maior digestibilidade em relação à pastagem tropical, o que pode ser observado pelo maior conteúdo do trato gastrintestinal da pastagem tropical em relação à pastagem temperada (Tab. 3). Macitelli et al. (2005) também observaram menor relação $\mathrm{PCV} / \mathrm{PAB}$ para animais que consumiram dieta de menor digestibilidade (cana-de-açúcar vs silagem de milho). A comparação da relação PCV/PAB entre estudos deve considerar, contudo, diferenças de tempo de jejum e tipo de dieta.

Os animais da pastagem tropical apresentaram maior $(\mathrm{P}<0,10)$ rendimento de carcaça quente em relação ao peso corporal vazio, quando comparados aos alimentados com pastagem temperada. Por outro lado, o rendimento de carcaça fria em relação ao peso corporal vazio não foi influenciado pelo sistema de alimentação. As carcaças dos animais da pastagem tropical apresentaram maior quebra durante 0 resfriamento em relação às dos animais da pastagem temperada, o que pode justificar a não diferença significativa no rendimento da carcaça após o resfriamento.

Os animais do confinamento apresentaram maiores pesos absoluto e relativo de sangue do que os animais terminados em pastagem tropical. Quanto maior os órgãos, maior a quantidade de sangue necessário para suportar a demanda metabólica desses animais (Pacheco et al., 2005). Diferentemente do observado por Kuss et al. (2007), no presente estudo não se observou correlação significativa entre o peso de sangue e o de conjunto dos órgãos internos (COI). No entanto, houve correlação entre a quantidade de sangue e o peso do coração $(\mathrm{r}=0,88 ; \mathrm{P}=0,004)$ e dos rins $(\mathrm{r}=0,75 ; \mathrm{P}=0,031)$ nos animais do confinamento, e não houve relação entre a quantidade de sangue e o peso de nenhum dos órgãos nos demais tratamentos. Kuss et al. (2007) levantaram a hipótese de que quanto maior a deposição de tecidos, maior é o aporte de sangue para a condução de nutrientes, o que se confirmou neste estudo, pois os animais que apresentaram maior ganho de peso diário foram os do confinamento (1,410kg/animal/dia), seguidos pelos da pastagem temperada $(1,200 \mathrm{~kg})$ e, por último, os da pastagem tropical $(0,666 \mathrm{~kg})$. A regressão do peso do sangue e do GMD foi significativa (sangue $=5,91-2,385 * \mathrm{GMD}$; $\mathrm{R}^{2}=0,26 ; \mathrm{P}=0,042$ ).

O fígado foi o único dos órgãos internos que sofreu influência $(\mathrm{P}<0,05)$ do sistema de alimentação, isto é, os animais da pastagem temperada apresentaram maiores valores absoluto e relativo deste órgão. Era esperado que os animais terminados em confinamento apresentassem maior peso desse órgão pelo maior aporte de nutrientes, principalmente via concentrado. Dos órgãos vitais, Owens et al. (1993) citaram que o fígado é o mais alterado frente às variações no consumo de alimentos, às exigências energéticas e às taxas metabólicas, pois participa ativamente no metabolismo dos nutrientes. Por outro lado, Lunt et al. (1986) observaram que o fígado de novilhos alimentados com dietas à base de volumosos era mais pesado que o dos alimentados com dietas à base de grãos. $\mathrm{Na}$ presente pesquisa, o maior peso do fígado dos animais alimentados com pastagem temperada se deve ao teor de proteína bruta dessa forrageira (22,7\%), bem mais elevado do que o das demais dietas - 10,0 e $9,6 \%$ para os animais do confinamento e da pastagem tropical, respectivamente. Silva et al. (2002) observaram aumento no peso do fígado de novilhos Nelore quando elevaram o teor de proteína bruta da dieta de 15 para $18 \%$, e não observaram diferença quando elevaram o teor de concentrado de 20 para 80\%. Esses autores atribuíram a ausência de resposta ao aumento da porcentagem de concentrado nas dietas ao bom valor nutritivo do volumoso utilizado, pois, mesmo a dieta com maior participação de volumoso, supriu nutrientes (energia) suficientes para o máximo desenvolvimento dos órgãos. Apesar de apenas o peso do fígado ter apresentado variação frente aos sistemas de alimentação, essa diferença já foi suficiente para afetar os pesos absolutos e relativos do conjunto dos órgãos internos. 
O conjunto dos órgãos internos não influenciou o RCQPCV em nenhum sistema de alimentação. Por outro lado, os pesos absolutos e relativos a $100 \mathrm{~kg}$ de PCV do coração apresentaram correlação positiva com o RCQPCV - r=0,75; $\mathrm{P}=0,030$ e $\mathrm{r}=0,77 ; \mathrm{P}=0,024$, respectivamente dos novilhos do confinamento. Verificou-se correlação negativa entre os pesos absolutos e relativos a $100 \mathrm{~kg}$ de PCV e o RCQPCV $r=-0,99 ; \quad \mathrm{P}=0,0437 \quad$ e $\quad \mathrm{r}=-0,99 ; \quad \mathrm{P}=0,0818$, respectivamente, entre os animais da pastagem temperada. Além disso, neste sistema, os pesos relativos correlacionaram-se positivamente com o RCQPCV - r=0,99; $\mathrm{P}=0,071$ e $\mathrm{r}=0,99$; $\mathrm{P}=0,007$, respectivamente.

Os novilhos da pastagem temperada apresentaram maiores pesos absolutos e relativos de rúmen-retículo do que os do confinamento ou da pastagem tropical (Tab. 3). Silva et al. (2002) observaram que o peso do rúmen-retículo diminui linearmente com o aumento da porcentagem de concentrado, atribuindo esse efeito ao menor teor de conteúdo gastrintestinal nos animais que receberam maior quantidade de concentrado. Macitelli et al. (2005) não observaram diferença no peso do somatório rúmen-retículo+omaso+abomaso ao alimentarem novilhos Nelore com cana-de-açúcar, silagem de milho ou pastagem de Brachiaria decumbens como volumoso. No presente estudo, houve correlação significativa entre o peso do rúmenretículo e o conteúdo do trato gastrintestinal nos animais do confinamento $(\mathrm{r}=0,79 ; \mathrm{P}=0,020)$ e da pastagem tropical $(\mathrm{r}=0,92 ; \mathrm{P}=0,026)$.

Tabela 3. Médias e erros-padrão das médias dos pesos absolutos e relativos a $100 \mathrm{~kg}$ de peso corporal vazio (PCV) dos órgãos componentes do trato gastrintestinal (TGI), do conteúdo do TGI (CTGI) e da gordura interna depositada em diferentes locais do corpo de novilhos da raça Devon, de acordo com o sistema de alimentação

\begin{tabular}{|c|c|c|c|}
\hline & Confinamento & Pastagem temperada $^{1}$ & Pastagem tropical $^{2}$ \\
\hline Rúmen-retículo, kg & $6,54 \pm 0,22 b$ & $7,62 \pm 0,35 a$ & $6,06 \pm 0,27 b$ \\
\hline Rúmen-retículo, \% PCV & $2,03 \pm 0,05 b$ & $2,30 \pm 0,08 a$ & $1,96 \pm 0,06 b$ \\
\hline Omaso, kg & $5,17 \pm 0,30 \mathrm{a}$ & $3,70 \pm 0,50 \mathrm{~b}$ & $4,77 \pm 0,40 \mathrm{ab}$ \\
\hline Omaso, \% PCV & $1,61 \pm 0,11 a$ & $1,12 \pm 0,17 b$ & $1,54 \pm 0,14 \mathrm{ab}$ \\
\hline Abomaso, kg & $1,40 \pm 0,07 b$ & $1,73 \pm 0,11 \mathrm{a}$ & $1,81 \pm 0,09 a$ \\
\hline Abomaso, \% PCV & $0,44 \pm 0,02 b$ & $0,53 \pm 0,04 \mathrm{ab}$ & $0,59 \pm 0,03 a$ \\
\hline Intestinos (IDG), kg & $5,52 \pm 0,42$ & $6,65 \pm 0,69$ & $5,17 \pm 0,54$ \\
\hline IDG, \% PCV & $1,72 \pm 0,14$ & $2,02 \pm 0,21$ & $1,67 \pm 0,17$ \\
\hline TGI, kg & $18,63 \pm 0,6$ & $19,70 \pm 1,0$ & $17,81 \pm 0,7$ \\
\hline TGI, \% PCV & $5,79 \pm 0,18$ & $5,97 \pm 0,30$ & $5,76 \pm 0,23$ \\
\hline CTGI, kg & $55,32 \pm 2,2 a$ & $41,21 \pm 3,5 b$ & $60,27 \pm 2,8 a$ \\
\hline CTGI, \% PCV & $17,15 \pm 0,7 \mathrm{~b}$ & $12,45 \pm 1,1 \mathrm{c}$ & $19,48 \pm 0,8 \mathrm{a}$ \\
\hline \multicolumn{4}{|c|}{ Local de depósito da gordura } \\
\hline Coração, kg & $0,65 \pm 0,10 \mathrm{~b}$ & $1,26 \pm 0,20 \mathrm{a}$ & $0,30 \pm 0,20 \mathrm{~b}$ \\
\hline Coração, \% PCV & $0,20 \pm 0,04 b$ & $0,38 \pm 0,07 a$ & $0,10 \pm 0,05 b$ \\
\hline Inguinal, kg & $1,76 \pm 0,14$ & $1,79 \pm 0,22$ & $1,38 \pm 0,17$ \\
\hline Inguinal, \% PCV & $0,45 \pm 0,03$ & $0,54 \pm 0,06$ & $0,37 \pm 0,04$ \\
\hline Rins, kg & $4,18 \pm 0,37$ & $4,75 \pm 0,61$ & $3,88 \pm 0,47$ \\
\hline Rins, \% PCV & $1,28 \pm 0,10$ & $1,44 \pm 0,16$ & $1,25 \pm 0,13$ \\
\hline Toalete, kg & $2,63 \pm 0,29$ & $2,33 \pm 0,48$ & $2,98 \pm 0,37$ \\
\hline Toalete, \% PCV & $0,81 \pm 0,08$ & $0,71 \pm 0,14$ & $0,96 \pm 0,11$ \\
\hline Rúmen, kg & $1,99 \pm 0,28$ & $1,30 \pm 0,46$ & $1,58 \pm 0,36$ \\
\hline Rúmen, \% PCV & $0,60 \pm 0,08$ & $0,39 \pm 0,12$ & $0,51 \pm 0,10$ \\
\hline Intestinos, kg & $7,13 \pm 0,52 b$ & $9,97 \pm 0,85 a$ & $7,49 \pm 0,66 b$ \\
\hline Intestinos, \% PCV & $2,22 \pm 0,17 b$ & $3,01 \pm 0,34 a$ & $2,42 \pm 0,21 b$ \\
\hline Total, kg & $18,85 \pm 1,0$ & $21,89 \pm 1,6$ & $18,53 \pm 1,2$ \\
\hline Total, \% PCV & $5,82 \pm 0,22 \mathrm{~B}$ & $6,63 \pm 0,35 \mathrm{~A}$ & $5,98 \pm 0,28 \mathrm{AB}$ \\
\hline
\end{tabular}


Diferentemente dos pesos do rúmen-retículo, o omaso dos animais do confinamento apresentou maiores pesos absolutos e relativos em relação ao omaso dos novilhos da pastagem temperada. Véras et al. (2001) e Ribeiro et al. (2001) verificaram decréscimo no peso do omaso com o aumento da participação do concentrado na dieta, e Jones et al. (1985) encontraram, proporcionalmente, maior tamanho do omaso para animais alimentados com dietas à base de forragem $(50 \%$ de silagem de milho $+50 \%$ de feno), quando comparados aos animais que receberam dietas à base de concentrado (30\% de silagem de milho $+70 \%$ de grão de milho com base na matéria seca). Segundo Van Soest (1994), o omaso promove absorção de água e realiza seleção do material que entra no abomaso, retendo as porções mais fibrosas. No presente estudo, a dieta com o menor teor de FDN foi a pastagem temperada, que também apresentou o menor peso do omaso. Além disso, observou-se que a silagem de milho apresentou, visualmente, algumas partículas grandes $( \pm 5 \mathrm{~cm})$, que provavelmente não foram bem trituradas e, com isto, foram retidas no omaso.

O abomaso foi mais pesado, em todas as formas de expressão, nos animais da pastagem tropical em relação aos do confinamento. Os resultados deste trabalho diferem da literatura. Véras et al. (2001) e Gesualdi Jr. et al. (2001) demonstraram que a variação no peso do abomaso está relacionada principalmente ao efeito nutricional. Segundo Ferrell et al. (1976), este órgão participa ativamente do processo de digestão, podendo ser maior em animais que recebem altos níveis de concentrado. Já Ribeiro et al. (2001) afirmaram que a musculatura e o volume do abomaso crescem em proporção aproximada aos ganhos de peso do corpo, de maneira independente da dieta.

Menezes et al. (2005) e Restle et al. (2005) associaram o maior rendimento de carcaça com o menor peso do trato gastrintestinal, relação não observada por Pacheco et al. (2006). No presente estudo, 0 peso do trato gastrintestinal correlacionou-se negativamente com o RCQPCV - $\mathrm{r}=-0,78 ; \mathrm{P}=0,0211$ - quando os animais foram terminados em confinamento. Na Tab. 3, nota-se que os tratamentos que apresentaram maiores $(\mathrm{P}>0,10)$ pesos do trato gastrintestinal foram os que apresentaram menor $(\mathrm{P}<0,10)$ rendimento de carcaça em relação ao PCV. A análise de regressão entre o TGI e os RCQPCV e RCFPCV foi significativa - RCQPCV = 76,53-0,688*TGI; $\mathrm{R}^{2}=0,53 ; \quad \mathrm{P}=0,001$ e $\mathrm{RCFPCV}=73,75-$ 0,625*TGI; $\mathrm{R}^{2}=0,58 ; \mathrm{P}=0,001$ ).

O conteúdo do trato gastrintestinal foi menor nos animais da pastagem temperada nas duas formas de expressão. Allen (1996) afirmou que o conteúdo de FDN da dieta é um dos principais responsáveis pelo enchimento ruminal e do trato gastrintestinal. $\mathrm{O}$ teor de FDN da pastagem temperada foi o mais baixo (32,9\%), seguido pelo teor de FDN da dieta do confinamento (34,6\%), e foi mais alto na pastagem tropical $(52,8 \%)$. Essa sequência foi seguida pelos pesos relativos do CTGI.

Apenas as gorduras depositadas no coração e nos intestinos sofreram influência do sistema de alimentação (Tab. 3). Em todas as formas de expressão, os novilhos da pastagem temperada apresentaram maior $(\mathrm{P}<0,05)$ depósito de gordura no coração e nos intestinos em relação aos terminados nos demais sistemas. Essa superioridade se refletiu no total de gordura interna expressa na forma relativa (PCV e PAB) entre os animais da pastagem temperada e do confinamento, sendo que os animais da pastagem tropical não diferiram $(\mathrm{P}>0,10)$ dos demais sistemas.

Jones et al. (1985) encontraram grande quantidade de gordura visceral em animais alimentados com dietas altamente energéticas, quando comparados aos de dietas medianamente energéticas. Esses resultados foram também encontrados por Ribeiro et al. (2001). No presente estudo, as densidades energéticas do confinamento e da pastagem temperada foram próximas, com leve superioridade da dieta do confinamento (3,09 versus 3,00Mcal/kg de MS). Vaz et al. (2007) atribuíram a pequena diferença numérica, de $2,1 \%$, na quantidade de gordura na carcaça a favor dos animais terminados em pastagem cultivada de inverno (azevém) sobre os terminados em confinamento à maior relação molar ácido acético - ácido propiônico na dieta dos animais em pastagem de azevém. Outra explicação pode estar relacionada ao consumo de nutrientes, pois, segundo a literatura, o consumo de matéria seca em animais em pastagem cultivada de inverno é mais alto que 3\% do peso vivo (Pilau et al., 2004), enquanto o consumo no presente estudo para os animais em 
confinamento ficou próximo a 2,2\% do peso vivo.

Segundo Carvalho et al. (2003), o peso da cabeça, patas e couro representa de 15 a $17 \%$ do peso vivo do animal. No presente estudo, o conjunto desses órgãos foi de $14,8 \%$ para os animais da pastagem tropical, 15,1\% para os do confinamento e $15,6 \%$ para os da pastagem temperada, e esses valores não diferiram entre si (Tab. 4). Quanto menor for o peso desses componentes, maior será o rendimento de carcaça.
A cabeça e a vassoura da cauda variaram com o sistema de alimentação, no entanto a medida desses componentes é passível de erros, uma vez que havia animais com ou sem chifres, o que pode acarretar diferenças no peso da cabeça. Quanto à vassoura da cauda, o erro pode estar embutido na altura do corte desse componente, pois o funcionário do frigorífico pode ter feito cortes diferentes, sugerido pelo alto coeficiente de variação observado (16,9\%).

Tabela 4. Médias e erros-padrão das médias dos pesos absolutos e relativos a $100 \mathrm{~kg}$ de peso corporal vazio (PCV) dos componentes externos não integrantes da carcaça de novilhos da raça Devon, de acordo com o sistema de alimentação

\begin{tabular}{lccc}
\hline & Confinamento & Pastagem temperada $^{1}$ & Pastagem tropical $^{2}$ \\
\hline Cabeça, kg & $14,91 \pm 0,30$ & $16,38 \pm 0,50$ & $15,08 \pm 0,30$ \\
Cabeça, \% PCV & $4,64 \pm 0,08 \mathrm{~B}$ & $4,95 \pm 0,13 \mathrm{~A}$ & $4,87 \pm 0,10 \mathrm{~A}$ \\
Patas, kg & $6,91 \pm 0,13 \mathrm{~b}$ & $7,12 \pm 0,21 \mathrm{ab}$ & $7,33 \pm 0,16 \mathrm{a}$ \\
Patas, \% PCV & $2,15 \pm 0,03 \mathrm{~b}$ & $2,16 \pm 0,05 \mathrm{~b}$ & $2,37 \pm 0,04 \mathrm{a}$ \\
VC, kg & $0,31 \pm 0,02 \mathrm{a}$ & $0,31 \pm 0,03 \mathrm{a}$ & $0,24 \pm 0,02 \mathrm{~b}$ \\
VC, \% PCV & $0,10 \pm 0,01 \mathrm{~A}$ & $0,09 \pm 0,01 \mathrm{AB}$ & $0,08 \pm 0,01 \mathrm{~B}$ \\
Couro, kg & $36,61 \pm 1,7$ & $36,47 \pm 2,8$ & $33,03 \pm 2,1$ \\
Couro, \% do PCV & $11,33 \pm 0,3$ & $11,06 \pm 0,7$ & $10,65 \pm 0,4$ \\
COE, kg & $58,73 \pm 1,9$ & $60,29 \pm 3,0$ & $55,69 \pm 2,3$ \\
COE, \% do PCV & $18,21 \pm 0,3$ & $18,26 \pm 0,6$ & $17,97 \pm 0,4$ \\
\hline
\end{tabular}

$\mathrm{VC}$ = vassoura da cauda; COE = conjunto dos componentes externos

Valores seguidos por letras minúsculas e maiúsculas diferentes, na linha, diferem entre si pelo teste $\mathrm{t}(\mathrm{P}<0,05)$ e $(\mathrm{P}<0,10)$, respectivamente.

${ }^{1}$ Pastagem de azevém.

${ }^{2}$ Pastagem com consorciação de milheto e capim-papuã.

Os animais da pastagem tropical apresentaram maior peso nas duas formas de expressão das patas em relação aos do confinamento. Essa diferença pode estar associada ao maior esforço físico a que os animais da pastagem tropical foram submetidos durante o pastejo, esforço que foi minimizado nos animais da pastagem temperada pelo menor tempo de alimentação 100, 75 e 47 dias para os animais da pastagem tropical, da pastagem temperada e do confinamento, respectivamente - para atingir o peso pré-estipulado.

De acordo com Pacheco et al. (2005), um subproduto do abate de bovinos muito valorizado pelos frigoríficos é o couro, que pode ser comercializado antes ou após a salga. Segundo dados do Anualpec (Anuário..., 2006), nos últimos cinco anos, a quantidade e o valor pago por kg de couro comercializado tanto no atacado como nas exportações foram crescentes, uma vez que este subproduto desempenha importante papel em outros segmentos da economia, destacando-se o da indústria de calçados e vestuário. O couro pode sofrer influência do peso (Restle et al., 2005) e da idade de abate (Pacheco et al., 2005) e do grupo genético (Menezes et al., 2007) do animal. Neste trabalho, o sistema de alimentação não influenciou o peso do couro em nenhuma das formas de expressão. 


\section{CONCLUSÕES}

O sistema de terminação influenciou os componentes não integrantes da carcaça, principalmente os pesos absolutos e relativos do fígado, do conjunto de órgãos internos, do rúmen-retículo, da gordura do coração e da gordura dos intestinos, que foram maiores em animais terminados em pastagem temperada. $\mathrm{O}$ peso do conteúdo do trato gastrintestinal foi maior nos novilhos terminados em pastagem tropical. Essas diferenças devem ser levadas em consideração no momento do cálculo de exigências nutricionais para animais terminados em diferentes sistemas de alimentação.

\section{REFERÊNCIAS BIBLIOGRÁFICAS}

ALLEN, M.S. Physical constraints on voluntary intake of forages by ruminants. J. Anim. Sci., v.74, p.3063-3075, 1996.

ANUÁRIO ESTATÍSTICO DA PRODUÇÃO ANIMAL. ANUALPEC. FNP. São Paulo: Prol Editora, 2006. 364p.

CARVALHO, P.A.; SANCHEZ, L.M.B.; VIEGAS, J. et al. Componentes do peso vivo e órgãos viscerais de bezerros machos de origem leiteira ao nascimento, 50 e 110 dias de vida, Rev. Bras. Zootec., v.32, p.1469-1475, 2003.

FERRELL, C.L.; GARRETT, W.N.; HINMAN, $\mathrm{N}$. Estimation of body composition in pregnant and non pregnant heifers. J. Anim. Sci., v.42, p.1158-1166, 1976.

GESUALDI Jr., A.; VELOSO, C.M.; PAULINO, M.F. et al. Níveis de concentrado na dieta de bovinos F1 Limousin x Nelore: Peso dos órgãos internos e trato digestivo. Rev. Bras. Zootec., v.30, p.1866-1871, 2001.

JONES, S.M.D.; ROMPALA, R.E.; JEREMIAH, L.E. Growth and composition of the empty body in steers of different maturity types fed concentrate or forage diets. J. Anim. Sci., v.60, p.427-433, 1985.

KUSS, F.; RESTLE, J.; BRONDANI, I.L. et al. Órgãos vitais e trato gastrintestinal de vacas de descarte mestiças Charolês $\times$ Nelore abatidas com pesos distintos. Rev. Bras. Zootec., v.36, p.421-429, 2007.
LUNT, D.K.; BYERS, F.M.; GREENE, L.W. et al. Effects of breed, diet, and growth rate on vital organ mass in growing and finishing beef steers. J. Anim. Sci., v.63, suppl.1, p.70-71, 1986.

MACITELLI, F.; BERCHIELLI, T.T.; SILVEIRA, R.N. de, et al. Biometria da carcaça e peso de vísceras e de órgãos internos de bovinos mestiços alimentados com diferentes volumosos e fontes proteicas. Rev. Bras. Zootec., v.34, p.1751-1762, 2005.

MENEZES, L.F.G.; RESTLE, J.; BRONDANI, I.L. et al. Características da carcaça de novilhos de gerações avançadas do cruzamento alternado entre as raças Charolês e Nelore, terminados em confinamento. Rev. Bras. Zootec., v.34, p.934945, 2005.

MENEZES, L.F.G.; RESTLE, J.; BRONDANI, I.L. et al. Órgãos internos e trato gastrintestinal de novilhos de gerações avançadas do cruzamento rotativo entre as raças Charolês e Nelore terminados em confinamento. Rev. Bras. Zootec., v.36, p.120-129, 2007.

NUTRIENT requirement of beef cattle. 7.ed. Washington, DC: National Academy, 1996. 232p.

OFFICIAL methods of analysis. Washington, DC: AOAC, 1984.

OWENS, F.N.; DONALD, R.G.; SECRIST, D.S. et al. Rewien of some aspects of growth and development of feedlot cattle. J. Anim. Sci., v.73, p.3152-3172, 1995.

OWENS, F.N.; DUBESKI, P.; HANSON, C.F. Factors that alter the growth and development of ruminants. J. Anim. Sci., v.71, p.3138-3150, 1993.

PACHECO, P.S.; RESTLE, J.; SILVA, J.H.S. et al. Relação entre componentes do corpo vazio e rendimentos de carcaça de novilhos de corte. Cienc. Anim. Bras., v.7, p.107-113, 2006.

PACHECO, P.S.; RESTLE, J.; SOUZA, J.H.S. et al. Características das partes do corpo não integrantes da carcaça de novilhos jovens e superjovens de diferentes grupos genéticos. Rev. Bras. Zootec., v.34, p.1678-1690, 2005.

PILAU, A.; ROCHA, M.G.; RESTLE, J. et al. Recria de novilhas de corte com diferentes níveis de suplementação energética em pastagem de aveia preta e azevém. Rev. Bras. Zootec., v.33, p.2104-2113, 2004. 
RESTLE, J.; MENEZES, L.F.G.; ARBOITTE, M.Z. et al. Características das partes não integrante da carcaça de novilhos 5/6 Nelore 3/8 Charolês abatidos em três estádios de desenvolvimento. Rev. Bras. Zootec., v.34, p.1339-1348, 2005.

RIBEIRO, T.R.; PEREIRA, J.C.; OLIVEIRA, M.V.M. et al. Características da carcaça de bezerros Holandeses, para a produção de vitelos recebendo dietas com diferentes níveis de concentrado. Rev. Bras. Zootec., v.30, supl., p.2154-2162, 2001.

SILVA, F.F.; VALADARES FILHO, S.C.; ÍTAVO, L.C.V. et al. Consumo, desempenho, características de carcaça e biometria do trato gastrintestinal e dos órgãos internos de novilhos Nelore recebendo dietas com diferentes níveis de concentrado e proteína. Rev. Bras. Zootec., v.31, p.1849-1864, 2002.

VAN SOEST, P.J. Nutritional ecology of the ruminant. 2.ed. New York: Cornell University, 1994. 476p.
VAZ, F.N.; RESTLE, J.; PADUA, J.T. et al. Qualidade da carcaça e da carne de novilhos abatidos com pesos similares, terminados em diferentes sistemas de alimentação. Cienc. Anim. Bras., v.8, p.31-40, 2007

VÉRAS, A.S.C.; VALADARES FILHO, S.C.; SILVA, J.F.C. et al. Efeito do nível de concentrado sobre o peso dos órgãos internos e do conteúdo gastrintestinal de bovinos Nelore não castrados. Rev. Bras. Zootec., v.30, supl.1, p.1120-1126, 2001.

WEISS, W.P.; CONRAD, H.R.; PIERRE, N.R. St. A theoretically-based model for predicting total digestible nutrient values of forages and concentrates. Anim. Feed Sci. Technol., v.39, p.95-110, 1992.

WILSON, J.R. Structural and anatomical traits of forages influencing their nutritive value for ruminants. In: INTERNATIONAL SIMPOSIUM ON ANIMAL PRODUCTION UNDER GRAZING, 1997, Viçosa. Anais... Viçosa: UFV, 1997. p.173-208. 